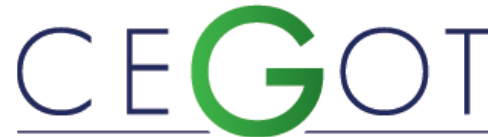

Centro de Estudos de Geografia e Ordenamento do Território
Fernandes, AleXANDRE

Universidade de Aveiro, Departamento de Ciências Sociais, Políticas e do Território

3910-193, Aveiro, Portugal

alexandrefernandes@ua.pt

SANTINHA, GONÇALO

Universidade de Aveiro, Departamento de Ciências Sociais, Políticas e do Território, GOVCOPP

3910-193, Aveiro, Portugal

g.santinha@ua.pt

FORTE, TERESA

Universidade de Aveiro, Departamento de Ciências Sociais, Políticas e do

Território, GOVCOPP

3910-193, Aveiro, Portugal

Teresaforte@ua.pt

Diogo, SARA

Universidade de Aveiro, Departamento de Ciências Sociais, Políticas e do

Território, CIPES

3910-193, Aveiro, Portugal

sara.diogo@live.ua.pt

\title{
Políticas locais e envelhecimento ativo: a realidade portuguesa à luz da perceção de diferentes atores
}

Local policies and active aging: the stakeholders' perspective of the portuguese reality

Referência: Fernandes, Alexandre; Santinha, Gonçalo; Forte, Teresa; Diogo, Sara (2020). Políticas locais e envelhecimento ativo: a realidade portuguesa à luz da perceção de diferentes atores. Revista de Geografia e Ordenamento do Território (GOT), no 20 (Dezembro). Centro de Estudos de Geografia e Ordenamento do Território, p. 79-104, dx.doi.org/10.17127/2020.20.004

\section{RESUMO}

A crescente proporção de idosos tem colocado vários desafios às políticas públicas em diferentes escalas. As diretrizes internacionais e nacionais têm subjacente a necessidade de promover um envelhecimento mais ativo e a importância de criar os meios necessários para que os decisores e demais atores relevantes trabalhem articuladamente para implementar políticas locais de envelhecimento ativo. Como é que estes atores entendem o conceito de envelhecimento ativo? Quais as prioridades de atuação? Que mecanismos de governança são usados para implementar essas políticas? Estas são algumas das perguntas que este artigo aborda no contexto português. Para responder a estas questões, recorreu-se a uma metodologia mista. Numa primeira fase, procedeu-se à aplicação de um questionário a diversos atores locais, a nível nacional, a fim de mapear as políticas locais de envelhecimento ativo. Em seguida, foi delineada uma abordagem de estudo de caso com base em entrevistas conduzidas em duas regiões NUTS III, de forma a estudar os respetivos mecanismos de 
governança relacionados com o tópico em análise. Os resultados corroboram o 'tipo de organização passiva' em que os estudos político-territoriais europeus tendem a colocar Portugal, dadas as lacunas na forma como as políticas são formuladas, implementadas e avaliadas, a que acresce uma falta de coordenação multinível.

Palavras-chave: Envelhecimento Ativo, Políticas Locais, Governança, População Idosa.

\section{ABSTRACT}

It is widely acknowledged that the rapidly rising share of older people is a challenge to public policies at different levels. Underlying international and national guidelines is the need to promote a more active ageing at par with a stronger collaboration between decision makers and other relevant stakeholders in the implementation of local active ageing policies. How are such stakeholders conceptualizing active ageing? What are their priorities? What governance mechanisms are used to implement such policies? These are some of the questions that this paper addresses in the context of a southern European country: Portugal. Mixed methods were used to address the issue at stake. In a first phase, a questionnaire was applied to local stakeholders, at a national level, in order to map local active ageing policies. Then, a case study approach based on interviews in two NUTS III regions was conducted to understand the governance mechanisms. Findings confirm the 'passive organization type' in which European politico-territorial studies tend to place Portugal, as there are gaps in the way policies are formulated, implemented and evaluated, besides the lack of multi-level coordination.

Keywords: Active ageing, Local policies, Governance, Local actors, Population ageing.

\section{Introdução}

Os dados demográficos atuais indicam que o envelhecimento da população é um fenómeno global, para o qual muito contribui a baixa taxa de natalidade dos países desenvolvidos. Prevê-se que, em 2050, o número de pessoas idosas supere o número de jovens em todo o mundo (Harper, 2010). No espaço Europeu, Portugal surge a seguir à Alemanha e Itália como o terceiro país mais envelhecido, com $21 \%$ da população com idade superior a 65 anos (EUROSTAT, 2019).

Enquanto desafio advindo da conquista de desenvolvimento e progresso da população, o envelhecimento populacional é também um importante indicador social, económico e político para a formulação de políticas públicas e a afetação de recursos no sentido de obtenção de maiores ganhos sociais e económicos e para uma correta definição de prioridades a serem executadas a curto e a médio/longo prazo (Kreling, 2010). Com efeito, e no que respeita a envelhecer na sociedade contemporânea, há uma preocupação crescente em desenhar políticas que suportem ações mais próximas das pessoas idosas e capacitem a 
sua autonomia e independência (Naue \& Kroll, 2010). A criação de mais oportunidades de participação e decisão, de acordo com as suas capacidades, pode contribuir para minimizar o impacto das transformações no estatuto que as pessoas idosas têm relativamente aos membros da sociedade (Fontaine, 2000). Este envelhecimento social, particularmente no que concerne às alterações dos papéis sociais exigidos/esperados pela sociedade em que a pessoa idosa se insere tem sido, tal como as transformações físicas e psicológicas típicas, alvo de várias representações tendencialmente enviesadas e pejorativas (Rossel, Herrera \& Rico, 2004).

Encarada como um grupo relativamente homogéneo até à década de 90, a imagem dominante da população idosa era a de dependência, fragilidade e sobrecarga para os recursos da comunidade. No contexto de uma sociedade de consumo que privilegia indivíduos ativos, a pessoa idosa era vista como um ser sem voz, sem ideias, fora do mercado e dos avanços científicos (Costa \& Santos, 2014). Estas prerrogativas idadistas,"atitudes e práticas negativas generalizadas em relação aos indivíduos baseadas somente numa característica - a sua idade" (Marques, 2011, p.18)- identificadas por Robert Butler no final dos anos 60, foram alvo de reflexão e crítica nas últimas década, em vários contextos culturais incluindo Portugal, no sentido de identificar e combater este tipo de manifestações e preconceitos contra as pessoas idosas. A premissa é eliminar o conceito de grupo homogéneo, caracterizado insistentemente por traços pejorativos (ex. doença e incapacidade), de sentimentos de desdém "mascarados" muitas das vezes por atitudes paternalistas e abusos e maus tratos mormente relacionados com esta faixa etária (Marques, 2011).

Nas últimas décadas, este grupo populacional recuperou algum poder social, sendo também representados como ativos e participativos. Para tal, muito contribuiu o aumento do nível de exigência e das expectativas que as pessoas idosas apresentam face às políticas públicas, fruto de maiores níveis de literacia/conhecimento. Estes avanços permitem que sejam as pessoas idosas a lutar pelos seus direitos económicos, sociais e culturais e a ter uma voz nas decisões que diretamente Ihes dizem respeito (Naue e Kroll, 2010). No entanto, Naue e Kroll (2010) alertam, ainda, para a ausência das pessoas idosas no que concerne à participação nos processos de formulação e implementação de políticas a si destinadas, com as 
organizações que as representam a delegar essas práticas a formas mais tradicionais e governamentais de formulação de políticas.

As diferentes características estruturais e culturais subjacentes ao fenómeno do envelhecimento populacional e à heterogeneidade de contextos territoriais em que ocorre, tem conduzido diversos autores a debater esta questão numa ótica de wicked problem para as políticas públicas (Rossel, Herrera \& Rico, 2004). E, por isso, o envolvimento e o reforço de mecanismos de articulação entre as diversas entidades públicas e não públicas nas diferentes escalas de intervenção central, regional e local é sublinhado pelos mesmos autores como fatores fundamentais para fazer face aos desafios que o envelhecimento populacional coloca à sociedade (Sander et al., 2015).

Esta articulação multinível e multissectorial deverá, em teoria, contribuir para o planeamento de estratégias de envelhecimento ativo, o que a Organização Mundial de Saúde (OMS), a Organização para a Cooperação e Desenvolvimento Económico (OCDE) e a Comissão Europeia (CE) referem concomitantemente como um processo de responsabilidade individual e coletiva que implica atividades produtivas, sejam elas económicas ou sociais, sem esquecer o bem-estar físico e mental (José \& Teixeira, 2014).

O envelhecimento ativo pode ser considerado como um objetivo e como um conceito político, na medida em que abarca, no mesmo espaço semântico, o envelhecimento saudável, bem-sucedido e produtivo (Fernández-Ballesteros et al., 2013). Estes alinham-se com esta perspetiva mais positiva do envelhecimento e que incentiva uma maior interação das pessoas idosas com a comunidade envolvente. $\mathrm{O}$ conceito de envelhecimento produtivo foi introduzido por Robert Butler, na década de 80 , e valoriza o papel desempenhado pela pessoa idosa, bem como os contributos que esta pode prestar na sociedade. O conceito de envelhecimento saudável, também definido nesta década por Rowe e Kahn, designa um conjunto de fatores que permitem à pessoa idosa continuar a funcionar eficazmente, tanto no plano físico como no plano psicológico (Gonçalves, 2015). Já o envelhecimento bemsucedido é definido como um processo de adaptação ao longo da vida, alicerçado em quatro domínios fundamentais: saúde física, funcionamento cognitivo, regulação emocional e motivação e participação social. Importa salientar o campo da regulação emocional, com os estudos neste âmbito a evidenciarem melhorias e ganhos ao nível do controlo, complexidade e autorregulação emocional, ao longo do processo de envelhecimento. Com 
efeito, as emoções positivas têm sido destacadas como fator ligado a um conjunto de conceitos psicológicos considerados como importantes determinantes individuais para o envelhecimento (Fernández-Ballesteros, 2008).

No que respeita às comunidades como um todo, importa referir as iniciativas inerentes às cidades saudáveis e às cidades amigas das pessoas idosas. A definição conceptual acompanha a que é descrita por parte da OMS, definindo um conjunto de indicadores que vão desde a organização do espaço físico, recursos, acessibilidade aos serviços, grau de participação social e necessidades básicas, que são essenciais na independência e participação das pessoas idosas na comunidade (OMS, 2008).

As políticas públicas no domínio do envelhecimento, formuladas a nível nacional ou emitidas no âmbito da União Europeia, devem ter como objetivo harmonizar os desequilíbrios sociais de uma sociedade envelhecida, que vão desde o sistema de pensões, da segurança social, à adoção de medidas limitativas e prejudiciais dos interesses dos aposentados e reformados (Pereira, 2011). Contudo, se considerarmos que cada local tem uma determinada configuração cultural própria, passível de influenciar uma certa cultura política e prática social dos seus atores, é possível argumentar que o "nível local" é de importância fundamental no processo de formulação de políticas, atuando, na prática, como mediador entre a administração central e a sociedade (Ruivo, 1990).

Tal importância é transversal a várias áreas, não sendo a área do envelhecimento uma exceção. Segundo a Age Platform Europe (2011), são precisamente os atores locais os mais habilitados a corresponder às necessidades e aos desafios que a população mais envelhecida enfrenta, na medida em que estão na vanguarda da capitalização das oportunidades para o envelhecimento ativo. Estes atores abarcam serviços e instalações em áreas como a educação, saúde, prática desportiva, transportes ou, até, políticas de emprego que são coerentes com boas práticas de envelhecimento ativo. A chave que abrirá as portas para uma maior qualidade de vida e bem-estar das pessoas idosas passa, em grande medida, pela adaptação destes atores aos desafios inerentes ao envelhecimento populacional.

Apesar das competências acima descritas, os municípios devem, porém, assimilar um modelo de governança em rede, ou seja, um modelo que preconize um processo contínuo de troca de ideias e de partilha entre diferentes setores. Emergindo com especial relevo a 
partir da década de 1990, o debate em torno deste conceito tem refletido as alterações das condições de governação observadas em diversos estados democráticos, havendo um reconhecimento generalizado de que o termo governança se refere ao desenvolvimento de diferentes formas de atuação em que a fronteira entre os setores público e privado se têm atenuado e a participação no desenho e implementação de políticas públicas deve ser alargada a um leque alargado de atores (Stoker, 2019). De acordo com Teles e Moreira (2016), a adoção deste modelo permite criar conjunturas institucionais e condições no tecido social que contribuam para a vitalidade de um conjunto complexo de relações e ligações fortes interinstitucionais.

Com o presente estudo, pretende-se contribuir para aumentar o parco conhecimento existente neste domínio das políticas públicas locais de apoio ao envelhecimento ativo, no contexto português e na perspetiva dos atores locais, através da exploração das seguintes questões: de que forma é que o poder local e demais atores conceptualizam o envelhecimento ativo? Quais os domínios prioritários subjacentes à promoção de um envelhecimento ativo (e.g. desenho urbano, estilos de vida saudáveis, suporte social e financeiro)? Como são projetadas e implementadas as políticas e quais os mecanismos de governança usados?

O remanescente do texto encontra-se estruturado da seguinte forma: na próxima secção é descrita a metodologia utilizada no presente estudo. Posteriormente é feita uma análise dos resultados (questionários e entrevistas), com uma síntese reflexiva. Por fim, em jeito de conclusão, tecem-se alguns comentários finais e recomendações para investigação futura.

\section{Metodologia}

O presente estudo centra-se nas políticas locais promotoras de envelhecimento ativo e na forma como as questões de governança interferem na formulação dessas mesmas políticas. Foi adotada uma abordagem metodológica mista definida como "um método de pesquisa que combina técnicas de investigação, métodos, abordagens, conceitos ou linguagem, quantitativos e qualitativos" (Johnson \& Onwuegbuzie, 2004, p.15). 
Numa primeira fase, e no sentido de mapear as visões sobre políticas locais implementadas em Portugal, procedeu-se à seleção de entidades com uma ação preponderante nas áreas que se cruzam com o conceito envelhecimento ativo (saúde, participação, segurança, aprendizagem ao longo da vida). Dentro de cada uma destas áreas, foram consideradas as organizações que, segundo a Estratégia Nacional para o Envelhecimento Ativo e Saudável 2017-2025, são mais dinâmicas na formulação e implementação de políticas/atividades deste teore mais próximas daspessoas idosas através de estruturas como a Rede Social e o CLAS.

Através desta amostragem não probabilística propositada, as seguintes instituições presentes em território continental e arquipélagos foram escolhidas e contactadas: Autarquias, Misericórdias (SCM), Unidades de Cuidados na Comunidade (UCC) e Universidades Sénior (US).

O questionário foi enviado entre dezembro de 2017 a junho de 2018 através de uma plataforma online, com recurso ao software "LimeSurvey", com um tempo de reposta média de 10 minutos. Todos os questionários foram remetidos ao decisor máximo da entidade, sendo que era dada liberdade para que este delegasse o seu preenchimento a outro técnico/responsável pela área do envelhecimento (situação maioritária com ênfase no departamento/secção da área social). Foi solicitado o preenchimento de apenas uma resposta por organização, considerando para o efeito a última resposta inserida, caso houvesse duplicação. Após envio para as entidades, foi efetuado um segundo contacto, quer a requerer o seu preenchimento, quer na confirmação do mesmo.

Nesta primeira fase, pretendia-se, por um lado, compreender se os atores tinham conhecimento de diferentes conceitos e noções associadas ao envelhecimento ativo e, por outro, mapear as iniciativas implementadas, numa perspetiva multinível.

O questionário aplicado incluía três secções. Na primeira, os participantes tiveram que identificar os principais conceitos relacionados com o envelhecimento e a respetiva fonte de conhecimento. Na segunda, tiveram de avaliar, através de uma escala de Likert (1 - maior prioridade e 5 - menor prioridade), o grau de prioridade subjacente a um conjunto de estratégias que o Conselho Local deveria adotar, de modo a enfrentar os desafios colocados pelo envelhecimento da população. Por fim, numa terceira secção, era pedido aos 
participantes que identificassem as políticas implementadas, entidades cooperantes e os resultados associados. Dados de carácter sócio-demográfico - idade, género/sexo, área de formação e anos de serviço - não foram solicitados pois não se pretendia analisar percepções e atitudes dos inquiridos enquanto decisores/técnicos. O objetivo era recolher informação por organização/ator local. Aos inquiridos foi-lhe pedido que indicassem apenas o cargo/serviço que desempenham na respetiva instituição. A classificação/descrição das funções dos entrevistados, e respetiva associação da área geográfica, foi feita de forma a não identificar os participantes.

Foram obtidas 482 respostas, das quais 162 completas e 320 incompletas. No final, e após uma análise detalhada consideraram-se 153 respostas elegíveis (salienta-se que só foram considerados válidos os inquéritos preenchidos na sua totalidade, com resposta a todas as questões. Houve 9 inquéritos duplicados, tendo-se analisado o último enviado até à data de término estipulada). Especificamente, o número de respostas por organização foi: Autarquias ( $n=96)$; SCM ( $n=23)$; UCC $(n=24)$ e US $(n=10)$, cuja distribuição geográfica está presente nas figuras 1 a 4 .

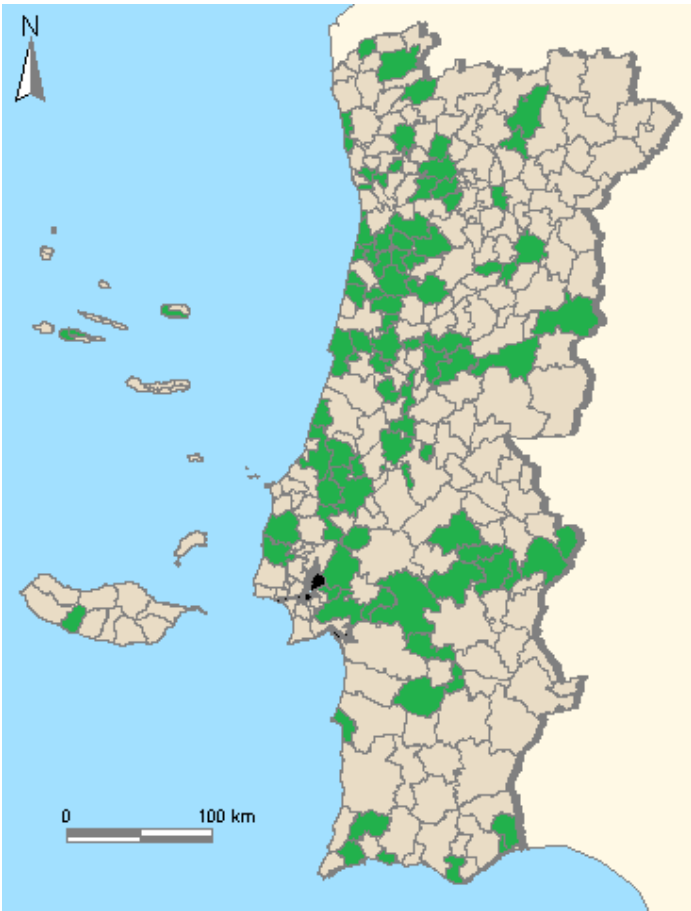

Figura 1 - Distribuição de respostas em autarquias Fonte:Elaboração própria

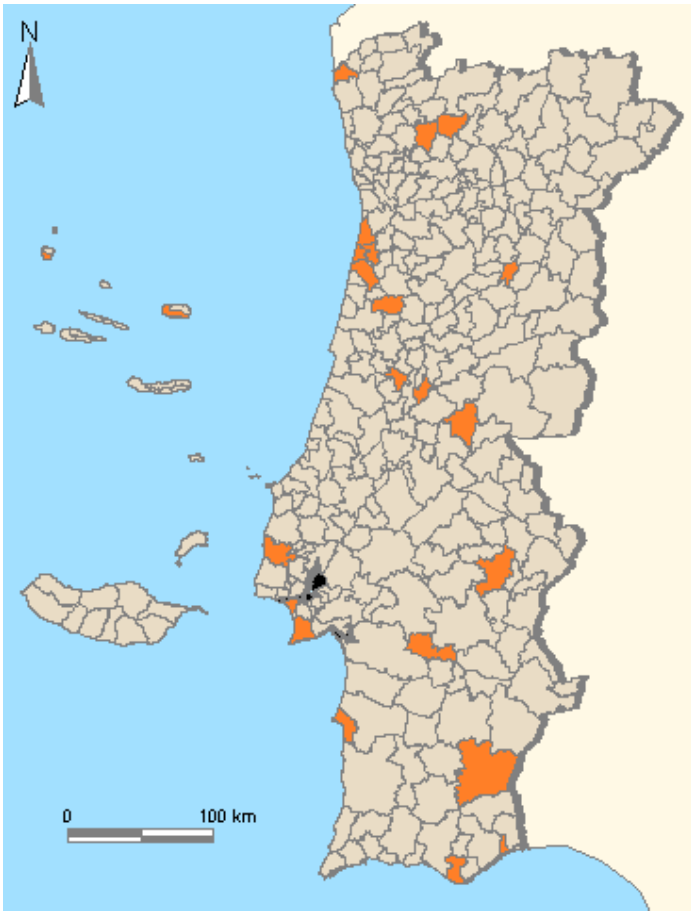

Figura 2 - Distribuição de respostas em SCM Fonte: Elaboração própria 


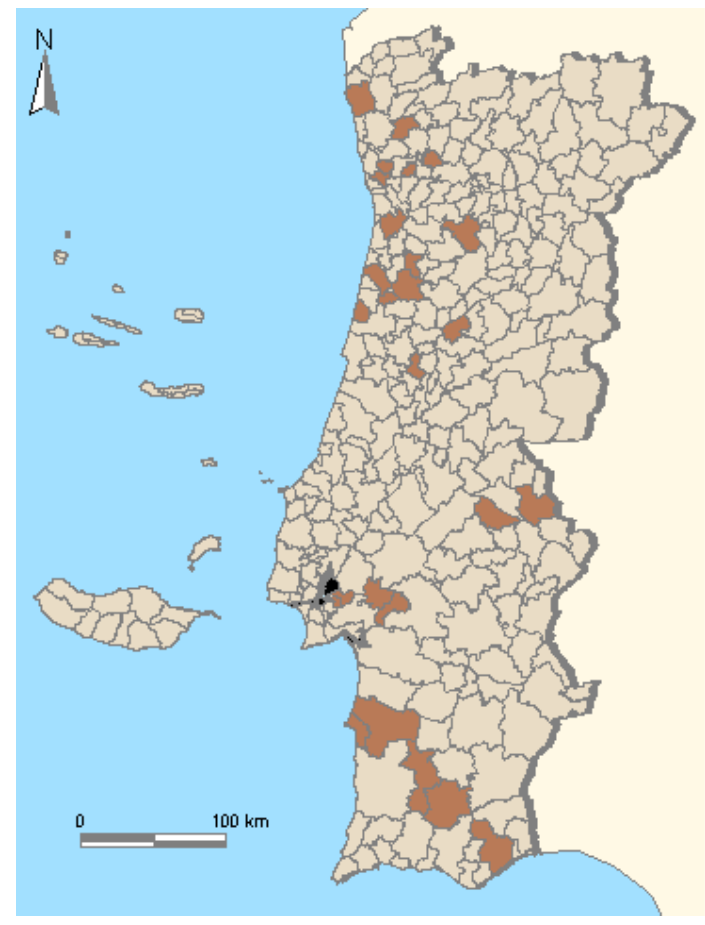

Figura 3 - Distribuição de respostas em UCC Fonte: Elaboração própria

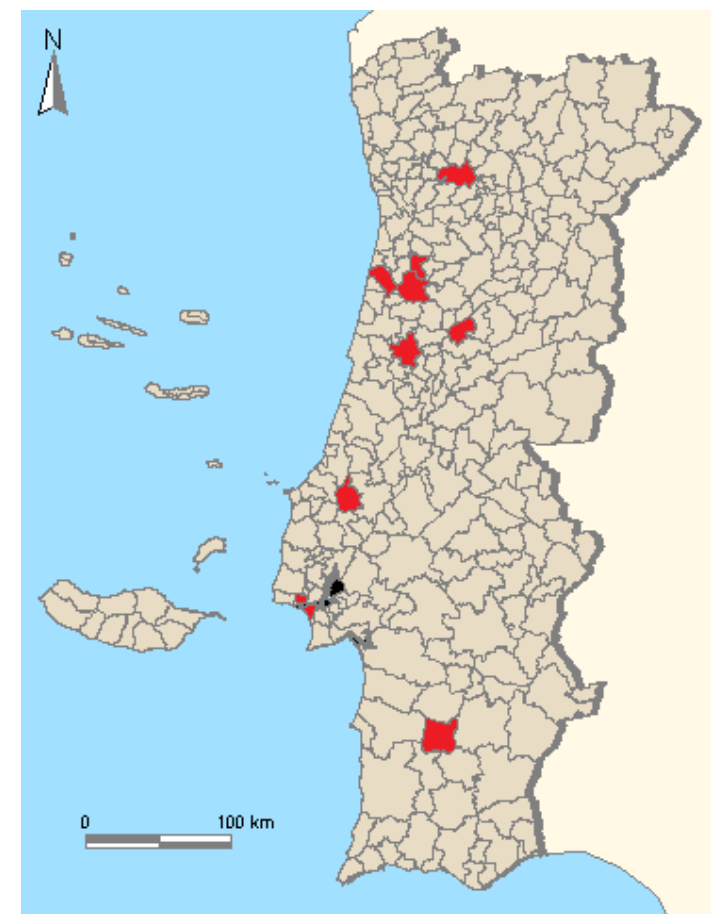

Figura 4 - Distribuição de respostas em US Fonte: Elaboração própria

No que respeita ao perfil dos inquiridos, o maior número de respostas nas Autarquias foi dado por elementos afetos à Divisão de Ação Social, sendo que 54\% $(n=52)$ eram Técnicos Superiores, $27 \%(n=26)$ Chefe de Divisão e 19\% $(n=18)$ afetos ao Executivo Municipal. Em SCM destaca-se o cargo de Diretor Técnico com 39\% ( $n=9)$ das respostas, seguido de Técnico Superior com 26\% ( $n=6)$, Chefe de Departamento com 17\% ( $n=4)$ e Provedor com $13 \%(n=3)$. Relativamente à US, o maior número de entrevistados desempenhava funções de Diretor, $50 \%(n=5)$, seguido de Presidente, $20 \%(n=2)$, com $10 \%(n=1)$ a ficarem ao cargo de professores. Por fim, relativamente ao cargo desempenhado pelos entrevistados em UCC, 54\% ( $n=13)$ dos entrevistados desempenhavam a função de Coordenador(a), seguidos de Enfermeiro(a) com 42\% ( $n=10)$ dos entrevistados e Fisioterapeuta, 4\% ( $n=1)$.

Após analisados os resultados dos questionários, decidiu-se explorar aprofundadamente o processo de formulação e implementação das políticas implementadas ao nível local e a forma como os atores trabalhavam e interagiam com as restantes entidades locais, regionais e nacionais. Para esta fase, selecionaram-se alguns atores chave da região de Aveiro e 
Coimbra - as duas regiões mais representativas na fase anterior e de contacto geográfico mais próximo - de forma a obterem-se informações adicionais por via da realização de entrevistas semiestruturadas. Nesta fase, dois aspetos foram abordados: (i) o processo de elaboração e implementação de políticas de envelhecimento ativo a nível local e (ii) a forma como os atores locais trabalham e interagem com as restantes entidades locais, regionais e nacionais, ao longo deste processo.

Após contacto prévio com todos os atores-chave das duas regiões analisadas, foram realizadas oito entrevistas. O número reduzido de entrevistas é explicado pela pouca disponibilidade apresentada pelas entidades contactadas, fator que, conjugado com o prazo estipulado no estudo, não permitiu ter um número mais representativo que possibilitasse uma análise territorial mais vasta. A ideia pré-estipulada seria, não só recolher informação mais detalhada sobre os dados adquiridos por via do questionário, mas também estabelecer um termo comparativo entre os atores das duas regiões.

O guião da entrevista estava estruturado em três secções. A primeira secção focava-se principalmente nos desafios que o envelhecimento ativo pode representar para o poder local, quer na definição de políticas, quer na implementação das mesmas. Na segunda parte da entrevista, pretendia-se analisar se as políticas implementadas eram articuladas/coordenadas com as restantes instituições promotoras de envelhecimento ativo do município, ou seja, se era observada uma articulação horizontal entre as várias entidades. Por fim, na terceira secção, e com base numa perspetiva multinível, pretendia explorar-se a interconexão entre as políticas definidas ao nível local com outros níveis de governação, nomeadamente, regional, central e europeu. Das oito entrevistas, cinco foram conduzidas a atores de Autarquias e as restantes três de SCM, UCC e US, respetivamente. A distribuição dos cargos exercidos dos entrevistados distribui-se da seguinte forma: dos entrevistados em Autarquias, quatro desempenham funções no Executivo Municipal (Região de Aveiro) e um apresentava funções de responsabilidade no departamento de Ação Social do município (Região de Coimbra). Quanto às entidades da SCM, da UCC e da US, as entrevistas foram efetuadas a diretores/coordenadores das respetivas entidades.

A análise descritiva dos dados do questionário foi efetuada com recurso ao software SPSS (versão 26.0) ao passo que nas entrevistas, após a sua transcrição integral, foi efetuada uma análise temática de conteúdo (Braun \& Clarke, 2006). Esta análise permitiu identificar e 
analisar a presença e prevalência de padrões (temas) nos discursos dos representantes das diferentes instituições no que se refere a dois grandes eixos de análise: i) o processo de elaboração e implementação de políticas de envelhecimento ativo a nível local; e ii) a forma como os atores locais interagem com as restantes entidades locais, regionais e nacionais.

Foi elaborada uma grelha de codificação com base em conceitos e temas presentes na literatura científica sobre envelhecimento ativo, incluindo temas mais genéricos e abrangentes (e.g. "Saúde e Bem estar"; "Factores culturais") e mais específicos e objetivos (e.g. "Processos de tomada de decisão; "Processos cognitivos e psicológicos"). A identificação dos temas nas entrevistas seguiu um critério semântico, codificando-se excertos textuais que se referiam explicitamente ao tema/código e efetuando-se uma análise de frequências para extrair a saliência dos temas nos discursos A codificação foi feita com recurso ao software Nvivo12.

\section{Análise dos resultados}

\subsection{Análise dos questionários - conceitos}

No que se refere aos conceitos da área do envelhecimento, mais de 90\% ( $n=148)$ dos inquiridos estavam familiarizados com "envelhecimento ativo" e "envelhecimento saudável". Estes são, de facto, os conceitos mais disseminados, sobretudo no contexto das autarquias com uma taxa de $99 \%(n=95)$.

O conceito de "envelhecimento produtivo" não se encontra tão disseminado. Nas SCM e em UCC apenas $43 \%(n=10)$ e $50 \%(n=12)$ dos inquiridos, respetivamente, estavam cientes da sua utilização. Colocou-se a hipótese deste desconhecimento resultar do facto de quase $50 \%$ dos inquiridos ( $n=23$ ) não desempenhar nenhum cargo de chefia ou de responsabilidade pela organização, não necessitando, como tal, de estar atualizado a esse nível. No entanto, $50 \%(n=23)$ dos participantes nestas posições também não conheciam o conceito. $O$ facto dos participantes das autarquias $(63 \% ; n=60)$ e US $(70 \% ; n=7)$ estarem mais familiarizados com esta noção sugere que o conhecimento seja contingente à natureza da área de atuação destas entidades. Com efeito, as SCM e UCC lidam maioritariamente com pessoas idosas com diversas fragilidades, sobretudo de saúde, o que não se coaduna com esta 
representação do envelhecimento, ao passo que as autarquias e US estão na linha da frente na promoção de um papel mais ativo para a pessoa idosa.

O mesmo padrão repete-se nos resultados dos conceitos de "cidades saudáveis" e "cidades amigas das pessoas idosas". Estes estão mais disseminados nas autarquias (88\%; n=84 ) (89\%; $n=85)$ e US (80\%; $n=8$, respetivamente) do que nas SCM, $(48 \% ; n=11)$ e $(57 \% ; n=13)$, e UCC, $(71 \% ; n=17)$ e $(67 \% ; n=16)$, o que é compreensível dado que a sua elaboração e implementação é da responsabilidade das autarquias.

A análise da origem do conhecimento desses conceitos corrobora a tendência acima descrita. Em autarquias, os conceitos advêm de orientação da própria instituição ou de orientação europeia, o que pode ser explicado, nomeadamente na primeira opção, pelo facto da maioria dos inquiridos serem técnicos superiores, ou seja, receberem a informação por normas emitidas pela entidade que os rege. No caso das SCM, os resultados são dispersos, mas podemos salientar o conceito de "envelhecimento produtivo" para atestar também a falta de conhecimento em cima analisada. Assim, verificamos que, por um lado, a maioria dos inquiridos teve conhecimento deste conceito por iniciativa própria e, por outro, apenas $10 \%$ por orientação da própria instituição, o que pode indiciar que este não é um conceito relevante para estes atores-chave. Por fim, em UCC, podemos aferir que os conceitos são na sua maioria obtidos por iniciativa própria e, muito raramente, por orientação da própria organização, o que pode revelar que estes atores-chave não estão despertos para estas questões. Em US, por contraste, o conhecimento advém maioritariamente da própria instituição

\subsection{Análise dos questionários - Visão}

$\mathrm{Na}$ análise efetuada às visões que estas entidades mais privilegiam, podemos concluir que, para as autarquias (ver tabela 1), as questões relacionadas com o desenho do espaço público e das barreiras arquitetónicas são vistas como menos prioritárias $(25 \%, n=24)$, o que pode indicar que já foram implementadas medidas de forma a resolver esta problemática. No entanto, pode também significar que as autarquias estão mais preocupadas, atualmente, com a promoção de estilos de vida saudáveis e atividades de lazer, esta sim, a visão prioritária e mais comum. 
Nas SCM (ver tabela 2), ao contrário do que acontece nas autarquias, a visão que reúne maior consenso é a que aborda as questões do desenho do espaço público. Esta conclusão pode ser explicada pelo facto da população idosa afeta a esta entidade apresentar maiores níveis de dependência. Por estas razões, a visão vista como menos prioritária é a que assenta no valor do contributo da população idosa nos processos de tomada de decisão, ou seja, não é reconhecido o valor e capacidade, por parte destas entidades, nas pessoas idosas que têm em mãos, devido ao facto de serem mais frágeis e dependentes por questões de saúde.

Nas US (ver tabela 3), os resultados são também, de certa forma, expectáveis. Se, por um lado, a visão vista como menos prioritária é a do desenho do espaço público, uma vez que os idosos que frequentam as universidades são, por norma, mais ativos e com boa mobilidade física, por outro lado, o valor acrescentado que a pessoa idosa pode apresentar nos processos de tomada de decisão é prioritário. Este facto pode ser explicado pelo perfil da população que frequenta esta entidade, por norma pessoas com maior autonomia e com capacidade intelectual preservada. Assim, os responsáveis querem incutir este tipo de visão nos seus associados, de forma a mostrar a eles e à sociedade o seu valor e a sua mais valia.

Por fim, nas UCC (ver tabela 4) o facto da população-alvo ser, por norma, mais dependente, tal como nas SCM, leva a que a visão menos prioritária seja a que reconhece o valor e contributo da população idosa nos processos de tomada de decisão. Já a maior prioridade assenta no fomento de uma boa rede de transportes que evite o isolamento social, facto que pode ser explicado pela mesma premissa, ou seja, o isolamento leva a dependência, que por sua vez leva à não participação. 
Tabela 1 - Visão das autarquias para fazer face ao envelhecimento populacional.

\begin{tabular}{|c|c|c|c|c|c|}
\hline Visão para o município & 1 & 2 & 3 & 4 & 5 \\
\hline $\begin{array}{l}\text { Ser um município cujo desenho do espaço público permite uma mobilidade } \\
\text { da população mais idosa, sem barreiras arquitetónicas e urbanísticas }\end{array}$ & $5 \%$ & $14 \%$ & $16 \%$ & $13 \%$ & $25 \%$ \\
\hline $\begin{array}{l}\text { Ser um município com uma boa rede de transportes, evitando o } \\
\text { isolamento social e promovendo o acesso aos serviços locais }\end{array}$ & $11 \%$ & $14 \%$ & $16 \%$ & $17 \%$ & $16 \%$ \\
\hline $\begin{array}{l}\text { Ser um município que promova estilos de vida saudáveis (atividade física, } \\
\text { promoção para a saúde, etc...), com atividades e eventos atrativos para a } \\
\text { população idosa }\end{array}$ & $27 \%$ & $15 \%$ & $13 \%$ & $9 \%$ & $10 \%$ \\
\hline $\begin{array}{l}\text { Ser um município que reconhece o valor do contributo da população idosa } \\
\text { nos processos de tomada de decisão, nomeadamente na organização de } \\
\text { atividades e eventos }\end{array}$ & $13 \%$ & $14 \%$ & $16 \%$ & $19 \%$ & $11 \%$ \\
\hline $\begin{array}{l}\text { Ser um município que apoie social e financeiramente a população idosa } \\
\text { mais carenciada }\end{array}$ & $17 \%$ & $18 \%$ & $14 \%$ & $15 \%$ & $9 \%$ \\
\hline Não Respondeu & & & $28 \%$ & & \\
\hline
\end{tabular}

Fonte: Elaboração própria

Tabela 2 - Visão das SCM para fazer face ao envelhecimento populacional.

\begin{tabular}{|c|c|c|c|c|c|}
\hline Visão para o município & 1 & 2 & 3 & 4 & 5 \\
\hline $\begin{array}{l}\text { Ser um município cujo desenho do espaço público permite uma } \\
\text { mobilidade da população mais idosa, sem barreiras arquitetónicas e } \\
\text { urbanísticas }\end{array}$ & $26 \%$ & $13 \%$ & $9 \%$ & $9 \%$ & $9 \%$ \\
\hline
\end{tabular}

Ser um município com uma boa rede de transportes, evitando $0 \quad 13 \% \quad 9 \% \quad 22 \% \quad 9 \% \quad 13 \%$ isolamento social e promovendo o acesso aos serviços locais

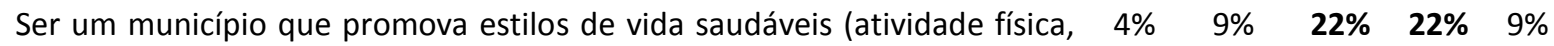
promoção para a saúde, etc...), com atividades e eventos atrativos para a população idosa

$\begin{array}{lllll}\text { Ser um município que reconhece o valor do contributo da população idosa } \quad 9 \% \quad 17 \% & 4 \% \quad 9 \% \quad \mathbf{2 6 \%}\end{array}$ nos processos de tomada de decisão, nomeadamente na organização de atividades e eventos

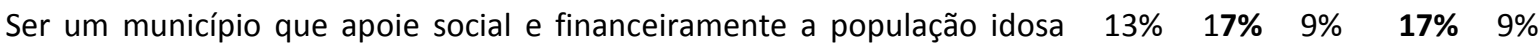
mais carenciada 
Tabela 3 - Visão das US para fazer face ao envelhecimento populacional

\begin{tabular}{|c|c|c|c|c|c|}
\hline Visão para o município & 1 & 2 & 3 & 4 & 5 \\
\hline $\begin{array}{l}\text { Ser um município cujo desenho do espaço público permite uma } \\
\text { mobilidade da população mais idosa, sem barreiras arquitetónicas e } \\
\text { urbanísticas }\end{array}$ & $10 \%$ & $10 \%$ & $10 \%$ & $10 \%$ & $30 \%$ \\
\hline $\begin{array}{l}\text { Ser um município com uma boa rede de transportes, evitando o } \\
\text { isolamento social e promovendo o acesso aos serviços locais }\end{array}$ & $0 \%$ & $20 \%$ & $20 \%$ & $20 \%$ & $10 \%$ \\
\hline $\begin{array}{l}\text { Ser um município que promova estilos de vida saudáveis (atividade física, } \\
\text { promoção para a saúde, etc...), com atividades e eventos atrativos para a } \\
\text { população idosa }\end{array}$ & $10 \%$ & $10 \%$ & $20 \%$ & $10 \%$ & $10 \%$ \\
\hline $\begin{array}{l}\text { Ser um município que reconhece o valor do contributo da população idosa } \\
\text { nos processos de tomada de decisão, nomeadamente na organização de } \\
\text { atividades e eventos }\end{array}$ & $30 \%$ & $20 \%$ & $0 \%$ & $10 \%$ & $20 \%$ \\
\hline $\begin{array}{l}\text { Ser um município que apoie social e financeiramente a população idosa } \\
\text { mais carenciada }\end{array}$ & $20 \%$ & $10 \%$ & $20 \%$ & $20 \%$ & $0 \%$ \\
\hline Não Respondeu & & & $30 \%$ & & \\
\hline
\end{tabular}

Fonte: Elaboração própria

Tabela 4 - Visão das UCC para fazer face ao envelhecimento populacional.

\begin{tabular}{|c|c|c|c|c|c|}
\hline Visão para o município & 1 & 2 & 3 & 4 & 5 \\
\hline Ser um município cujo desenho do espaço público permite uma mobi & $13 \%$ & $4 \%$ & $17 \%$ & $21 \%$ & \\
\hline
\end{tabular}

da população mais idosa, sem barreiras arquitetónicas e urbanísticas

Ser um município com uma boa rede de transportes, evitando o isolamento $\quad \begin{array}{lllll}17 \% & \mathbf{2 9} \% & 4 \% & 0 \% & 13 \%\end{array}$ social e promovendo o acesso aos serviços locais

Ser um município que promova estilos de vida saudáveis (atividade física, $\quad \begin{array}{llllll}17 \% & \mathbf{8} \% & \mathbf{2 1} \% & \mathbf{1 7 \%} & \mathbf{0} \%\end{array}$ promoção para a saúde, etc...), com atividades e eventos atrativos para a população idosa

Ser um município que reconhece o valor do contributo da população idosa $\quad 8 \% \quad 8 \% \quad 8 \% \quad 4 \% \quad 33 \%$ nos processos de tomada de decisão, nomeadamente na organização de atividades e eventos

Ser um município que apoie social e financeiramente a população idosa mais $\quad 8 \% \quad \begin{array}{lllll}13 \% & 13 \% & \mathbf{2 1} \% & 8 \%\end{array}$ carenciada 


\subsection{Análise dos questionários - Políticas e iniciativas desenvolvidas}

Após a análise dos conceitos e da visão das instituições em estudo face ao fenómeno do envelhecimento, importa agora identificar e analisar as iniciativas implementadas de modo a efetuar um retrato daquilo que é feito em território português. Grande parte das iniciativas são formuladas e implementadas pelas autarquias, o que confirma algumas das suposições iniciais, dada a cultura/tradição política portuguesa (figura 5).

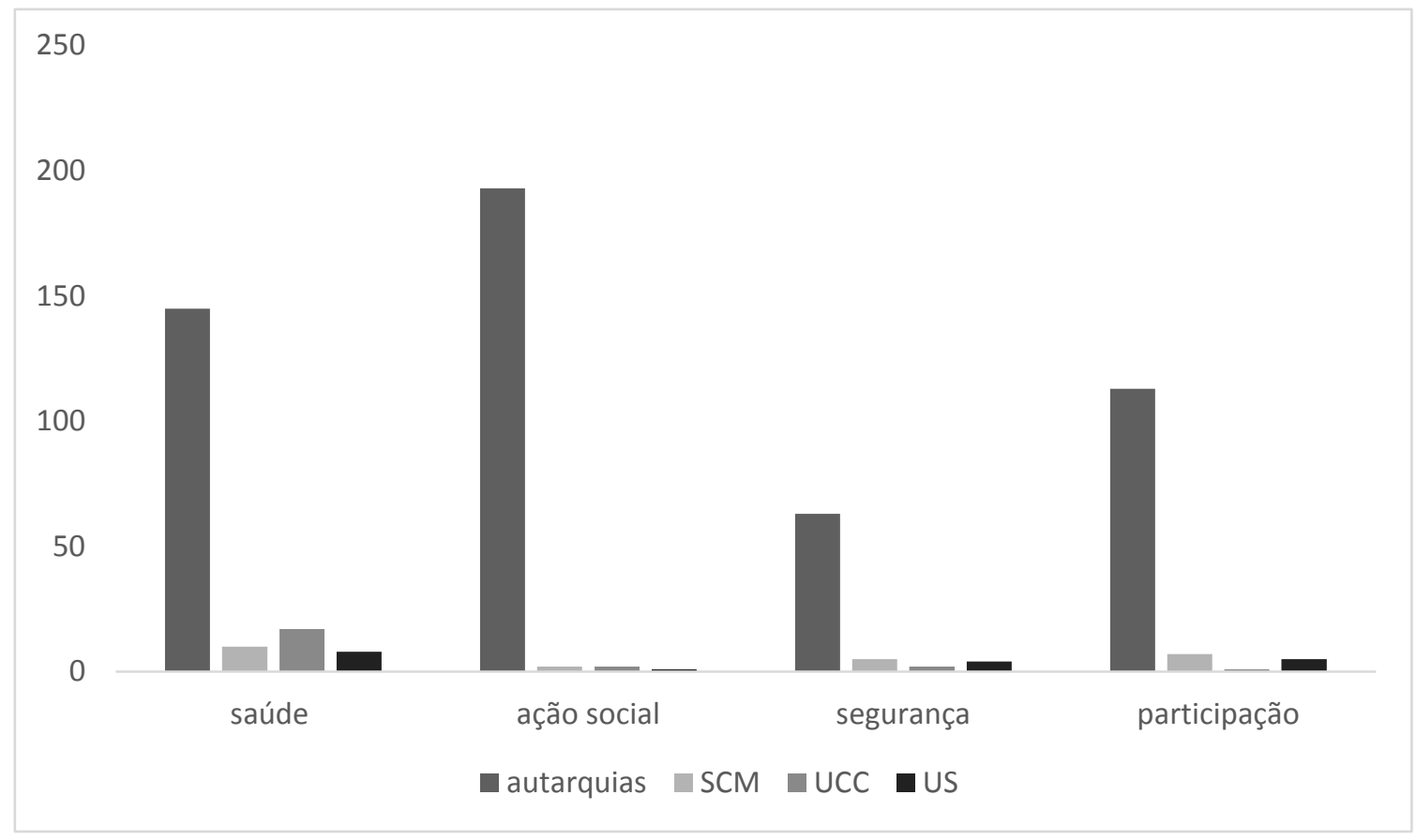

Figura 5 - Número de iniciativas implementadas por área

Fonte: Elaboração própria

A área que reúne um maior número de iniciativas é a da ação social, especificamente em iniciativas e políticas que provêm de apoios e benefícios, a maioria das vezes de cariz financeiro. Em segundo lugar, aparecem iniciativas na área da saúde, maioritariamente na área de promoção da educação para a saúde e atividades desportivas. É notório o trabalho em rede que é feito ao nível local na formulação e implementação das políticas e iniciativas. $\mathrm{Na}$ esmagadora maioria, existem sempre parcerias locais nas iniciativas implementadas nas entidades em estudo. A autarquia (ver figura 6) é a entidade com mais parcerias, nomeadamente através da Rede Social, "um dispositivo de planeamento e execução de políticas públicas participadas e um instrumento potenciador de sinergias e de uma ação coerente para o desenvolvimento de um estado social ativo" (IESE, 2012, p.7). 
Importa, ainda assim, salientar a escassez de iniciativas que têm parcerias com entidades de âmbito nacional e, ainda, a ausência de avaliação dos resultados das iniciativas implementadas.

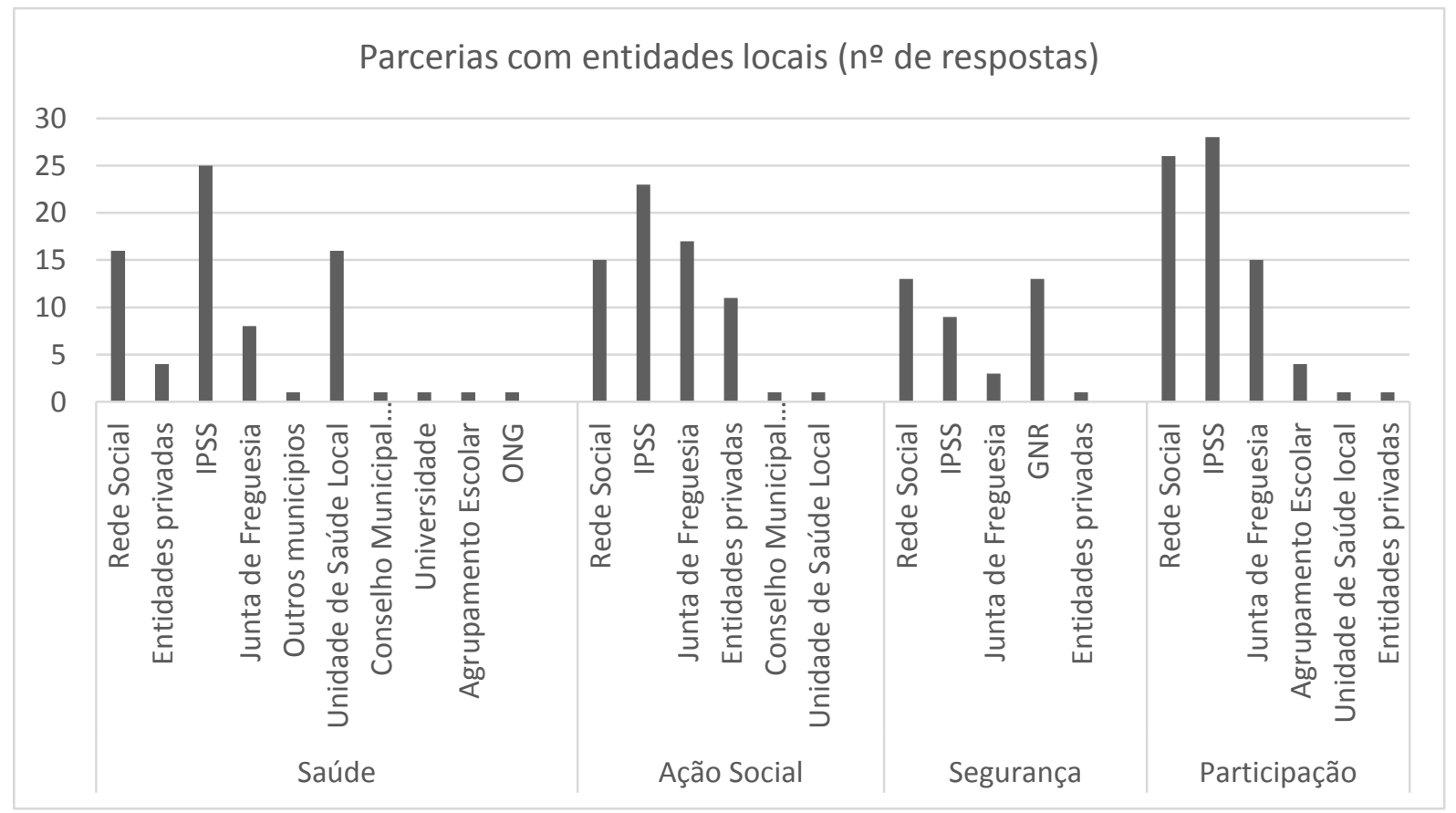

Figura 6 - Parcerias com entidades locais, em autarquias

Fonte: Elaboração própria

\subsection{Breve análise das entrevistas}

As entrevistas efetuadas posteriormente reforçaram algumas das conclusões dos questionários, contribuindo também para clarificar o processo de formulação e implementação das políticas e iniciativas desenvolvidas e respetivos os mecanismos de governança. A análise demonstrou a saliência de certos temas nos discursos dos entrevistados confirmando-se a prioridade de implementar nos respetivos municípios programas que visem a promoção de estilos de vida saudáveis, a prática de desporto e atividades de lazer. A participação dos idosos ao nível comunitário e social é outro aspeto muito relevante no discurso dos entrevistados. Um outro tema saliente e comum refere-se ao trabalho em rede ao nível local, consensualmente considerado fulcral na formulação e implementação de iniciativas de promoção do envelhecimento activo. Estas redes são 
propiciadas em grande parte pelas autarquias, nomeadamente através de estruturas como a Rede Social e o Concelho Local de Ação Social (CLAS) - plataforma de debate, de âmbito concelhio, que assenta na participação, representação e articulação entre organismos públicos e iniciativa social privada (Decreto-Lei n.o 115/2006).

O trabalho desenvolvido ao nível do CLAS e da Rede Social tem sido fundamental no contexto de envelhecimento ativo, dado o seu potencial em colocar as entidades locais a trabalhar para uma causa comum.

As Comunidades Intermunicipais (CIM) e as Plataformas Supra Concelhias (PSC), estas últimas enquanto órgãos da Rede Social criadas com o objetivo de reforçar a organização dos recursos e o planeamento das respostas e equipamentos sociais ao nível supraconcelhio, desempenham um papel importante, fundamentalmente na forma como coloca a debate o que rodeia o envelhecimento e na partilha entre os diversos atores. Refere Tsukamoto (2017), que as CIM trazem a vantagem para os municípios de poder rentabilizar a prestação de serviços partilhados, face à necessidade de poupar recursos financeiros em áreas da administração e de controlo de execução dos fundos comunitários que são, em cada ciclo, mais escassos para as autarquias. Convém, no entanto, alertar para o facto de a maioria das entrevistas ter-se realizado na Comunidade Intermunicipal de Aveiro, excetuando o município de Montemor-o-Velho, o que faz com que não haja um termo de comparação com outras realidades regionais. E, com efeito, parece haver na CIM da região de Aveiro um trabalho que tem sido otimizado pelos municípios da região, no que respeita à área do envelhecimento.

Uma vez mais, quanto ao processo de formulação e implementação das políticas e iniciativas, há que realçar as autarquias entrevistadas na região de Aveiro, que procuram efetuar estudos junto da população, de forma a sinalizar os problemas existentes e definir planos de ação que os combatam. Já no município de Montemor-o-Velho, estes processos, por norma, não são efetuados. No estudo de Barbosa (2015, p.65) que, em Portugal, se centra na Área Metropolitana de Lisboa, é identificada uma fraca cultura de formulação e implementação de políticas locais promotoras de envelhecimento ativo, visto que "o papel das autarquias locais está sobretudo relacionado com equipamentos e programas de combate à pobreza e exclusão social". 


\subsection{Quadro síntese de análise}

Nas entrevistas e nos questionários foi possível identificar uma fraca articulação entre o poder local e respetivas entidades com os poderes intermédios e centrais, principalmente naquilo que são e devem ser as competências de cada um. Refere Barbosa $(2015$, p.65) que “Portugal apresentava um modelo local que reclamava a ausência de orientações top-down, sendo o envelhecimento visto e intervencionado, sob o ponto de vista da provisão de programas e projetos de cariz lúdico, social e de aprendizagem, sem, no entanto, existirem orientações centrais nesta matéria". Esta situação potencia uma disparidade entre diversas realidades locais, ou seja, há uma capacidade distinta de encarar este fenómeno demográfico, quer pelos atores intervenientes, quer pela própria capacidade financeira do município, o que, em último caso, gera velocidades diferentes na resolução destas questões. No entanto, de acordo com Matos (2013), a articulação multinível está prevista através da ligação entre o CLAS, de base concelhia, e as PSC (NUT III), que deverão ficar ligadas, a nível nacional, ao Instituto da Segurança Social, que, por sua vez, faz a ponte com o Governo. Através deste modelo de organização estão criadas as condições formais para que seja possível uma articulação entre os vários níveis de poder, nomeadamente, ao nível de atores e de políticas e instrumentos. Sendo certo que nas entrevistas realizadas na região de Aveiro são referenciados estes vários níveis de articulação, não é menos verdade que no discurso dos entrevistados transparece que falta esta ponte entre as PSC e o poder central, pois o trabalho entre o CLAS e as PSC tem sido efetuado com alguma regularidade.

O poder local queixa-se da falta de apoios financeiros e essencialmente da falta de legislação e diretrizes daquilo que podem e devem fazer, ou seja, há uma falta de partilha de informação num sentido bidirecional. Ao nível de iniciativas de âmbito nacional e europeu, há uma maior visão por parte das autarquias da região de Aveiro entrevistadas, havendo alguns programas implementados. No entanto, pelo que foi dado a observar nos inquéritos, existe uma escassez a este nível. Num outro estudo efetuado por Bárrios (2017), a autora alertava para as reduzidas diretrizes europeias no âmbito do envelhecimento ativo, não sendo esta ainda uma das prioridades da UE. Contundo, com a realização do presente estudo, ficamos com a perceção de que os atores locais têm desconhecimento das diretrizes emanadas pela União Europeia, conduzindo, consequentemente, a uma perda de 
oportunidades para a implementação, por exemplo, de programas com fundos comunitários.

A figura 7 apresenta uma sistematização da análise acima descrita. Uma leitura do esquema mostra que a interligação dos diferentes níveis de poder (central, regional e local) é díspar, notando-se uma falha comunicacional ou de limitação de funções entre o poder regional e central. O papel desempenhado pelas CIM e pelas PSC tem de ser solidificado, na medida em que têm de servir como elo entre o governo e respetivas entidades da administração central e as organizações do poder local. Neste ponto, verifica-se uma ausência nos papéis que cada nível deve desempenhar, ou seja, que responsabilidades estão ou deveriam estar imputadas ao poder central e quais as que deveriam estar claramente descentralizadas. Importa realçar que as CIM e as PSC são importantes locais de debate entre os atores locais de cada território, quer pela troca e partilha de experiências, quer pelas iniciativas de benchmarking depois postas em prática. Além disso, é importante que cada região, pela respetiva semelhança demográfica/territorial e populacional, tenha uma estratégia de formulação de políticas congruente e bem estruturada face às necessidades que acarreta no âmbito do envelhecimento ativo.

$\mathrm{Na}$ base do esquema procura mostrar-se que, de acordo com a informação recolhida quer por via dos questionários quer através das entrevistas, o papel das autarquias é fundamental na criação e formulação de iniciativas ligadas ao envelhecimento ativo. O grosso das medidas implementadas vêm destas entidades, inclusive no desenvolvimento de um trabalho em rede com as restantes entidades locais. Aqui verifica-se que estruturas como a Rede Social e o CLAS são importantes na dinamização e debate em torno de um trabalho coeso e sem sobreposição, focado nas necessidades inerentes a cada população e território. De realçar que a maioria das iniciativas locais se prende com benefícios sociais e atividades que apoiam a prática de estilos de vida saudáveis, nomeadamente, quando analisamos as autarquias. No que concerne às restantes entidades analisadas, observam-se, complementarmente a estas, iniciativas de cariz mais direcionado ao seu eixo de intervenção. 


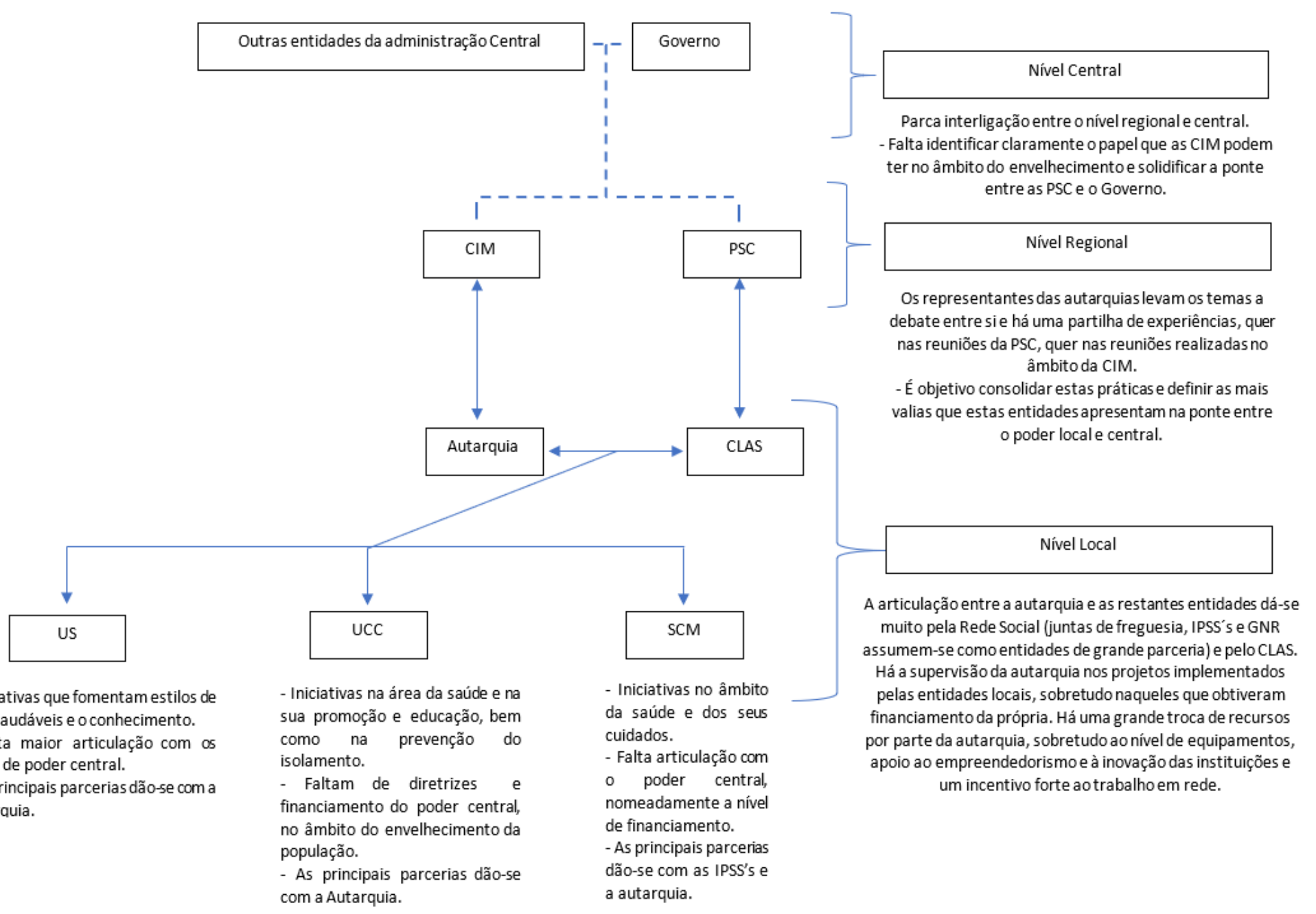

Figura 7 - Quadro síntese de análise

Fonte: Elaboração própria 


\section{CONCLUSÃO}

A recolha e a análise das principais políticas locais promotoras de envelhecimento ativo, compreendendo os mecanismos de governança na sua formulação e implementação, permitiram compreender que existe uma clara ausência de articulação entre níveis de poder. Segundo a AGE Platform Europe (2011), os atores locais e regionais podem tirar partido de muitos programas europeus de financiamento que apoiam o desenvolvimento de práticas e investigação inovadoras, bem como fomentar a cooperação entre regiões. No entanto, com base nos resultados deste estudo é possível afirmar que há ainda um longo caminho a percorrer, sobretudo se o envelhecimento for pensado como uma etapa que requer um conjunto de medidas mais abrangentes do que iniciativas e atividades de promoção de estilos de vida saudáveis. Note-se, a este respeito, que os resultados também sugerem que os municípios que estão atentos a estas questões são os que, por norma, se encontram mais capacitados para lidar com a população idosa, dispondo de mais e melhores meios, uma vez que as verbas disponibilizadas pelo poder central são insuficientes para solucionar a maioria dos problemas.

Se é certo que cada vez mais os agentes políticos pensam e debatem as questões do envelhecimento da população, não é menos verdade o que nos dizem Walker \& Maltby (2012) quando referem que, apesar do "envelhecimento ativo" estar presente nas orientações da $\mathrm{CE}$, não é sinónimo de que as políticas pensadas e delineadas estejam a ser postas em prática e, subsequentemente, a cumprir o papel que a UE tinha definido para elas. As questões são diversas, desde o intervalo de tempo entre a formulação e implementação dessas mesmas políticas ao vasto campo de ação que norteia o envelhecimento, ou até mesmo à que é a questão fulcral da UE e que se prende com as políticas de emprego.

A adoção de um modelo de governança em rede adquire uma importância acrescida na formulação e concretização das políticas e iniciativas de envelhecimento ativo, na medida em que o envelhecimento é um fenómeno multidimensional, implicando, por isso, medidas conjuntas (em rede) e não isoladas, envolvendo atores de esferas distintas. Desta forma, a sinalização dos problemas é mais eficaz e a partilha entre todas as entidades aumenta o sucesso dos planos de ação, com a população idosa a sair mais beneficiada. 
A Rede Social é uma forte alavanca para agregar e colocar os agentes locais em constantes parcerias e, de certa forma, consciencializar as entidades locais para contemplar o trabalho em rede na formulação das suas políticas. No entanto, a ausência de uma visão multinível (englobando o nível central) potencia dinâmicas e iniciativas circunscritas à promoção de estilos de vida saudáveis e atividades de lazer e ocupação, continuando a não existir diretrizes por parte da administração central que sirvam como orientação para o poder local expandir as áreas de intervenção. Mesmo quando se pensa numa estrutura intermédia, nomeadamente ao nível das CIM, foi identificada pelos entrevistados a necessidade destas estruturas servirem como um local de debate e partilha, de implementação de políticas, de esclarecimento e, acima de tudo, de monitorização do que está a ser colocado em prática.

Outra das questões visíveis neste estudo centra-se na formulação das políticas e o desenvolvimento de iniciativas. Como argumentava um dos entrevistados, a "formulação faz-se consoante aquilo que é possível" e muitas vezes a sinalização dos problemas advém da população e das suas inquietações. Segundo Ferrão (2015), a governação multinível ganha relevância como peça fundamental na formulação e concretização de políticas públicas cuja eficácia e eficiência resulta, justamente, da sua adequação às necessidades, prioridades e capacidades dos atores, privados e públicos e de espaços pertinentes para o efeito.

É certo que os resultados alcançados neste estudo mostram só parte da realidade nacional, cuja compreensão detalhada decorrente da realização das entrevistas deve ser encarada de uma forma contextualizada. Mas não é menos verdade que o estudo efetuado permitiu, ainda assim, adquirir um maior conhecimento sobre o que está a ser delineado a nível local no âmbito do envelhecimento ativo e sobre os mecanismos inerentes ao processo de formulação e implementação de políticas públicas. Em primeiro lugar, foi possível identificar as áreas em que as entidades mais incidem e que passam pela promoção de estilos de vida saudáveis e de iniciativas de ocupação e lazer, com uma aposta muito grande por parte das autarquias na área da ação social, nomeadamente em medidas relacionadas com apoios e benefícios financeiros. Em segundo lugar, foi possível observar uma cultura de formulação e implementação de políticas em rede, alicerçada na sua maioria pela Rede Social. Por fim, importa salientar a ausência de orientações por parte da administração central nestas matérias, bem como a reduzida interligação entre os vários níveis de governação. Neste 
âmbito, foi possível observar que um nível intermédio de governação pode ser a chave para estas questões, com as CIM e as PSC a constituírem importantes fóruns de debate e partilha entre os vários municípios de uma região.

Importa, por fim, referir aquelas que foram as limitações deste estudo, por forma a possibilitar uma melhoria nos quadros teórico-práticos e na metodologia utilizada em estudos futuros. A primeira limitação prende-se desde logo com aquela que foi a maior batalha deste trabalho: o número de inquiridos. A obtenção de um maior número de respostas permitiria o desenvolvimento de conclusões mais robustas e perceber melhor as dinâmicas e processos multiníveis nas políticas de envelhecimento ativo. Além disso, seria interessante mapear em território português essas mesmas políticas, de forma a perceber as realidades entre áreas geográficas (litoral/interior ou zonas rurais/urbanas) e assim poder haver um meio de comparação, nomeadamente com o estudo efetuado pelo Progress Consulting S.r.l. e Living Prospects Ltd que procura identificar as soluções adotadas a nível local e regional por parte dos países da UE para enfrentar os desafios relacionados com o envelhecimento. Refira-se, uma vez mais, a ausência de estudos de fundo e transversais efetuados em Portugal. Até à data destacam-se os estudos de Barbosa (2015) e de Bárrios (2017) que abordam esta temática, mas em contextos territoriais específicos. A procura no presente estudo em tentar mapear numa primeira fase todas as políticas de envelhecimento em território nacional procurou constituir uma base de referenciação, de forma a estabelecer padrões generalizados, o que constituía um avanço cientifico relevante, embora a amostra não tenha sido suficiente para tecer as devidas conclusões.

Outra das limitações prende-se com o facto do estudo se centrar exclusivamente na auscultação de atores locais. Seria interessante obter também os testemunhos de atores regionais e nacionais, de forma a perceber como perspetivam o envelhecimento a nível local (numa ótica de articulação multinível) e que estratégias deveriam ser adotadas para este efeito.

Finalmente, seria também importante comparar a realidade portuguesa com outros países europeus, de forma a perceber as diferenças e semelhanças entre os mesmos. A forma como os países se norteiam pelas orientações europeias, ou falta delas, é um fator merecedor de análise, uma vez que o envelhecimento demográfico não é uma questão futura, mas sim uma realidade presente. Seria ainda relevante aplicar-se a metodologia aqui 
utilizada noutras regiões do território português, de modo a perceber se algumas das conclusões aqui retiradas estão dependentes do contexto regional, ou pelo contrário, podem ser extrapoladas para o panorama nacional.

\section{Referências Bibliográficas}

Age Platform Europe. (2011, set.). How to promote active ageing in Europe - EU support to local and regional actors. Bruxelles: Committee of the Regions. Disponível em https://udruge.gov.hr/.

AGE Platform Europe. (2011). How to promote active ageing in Europe - EU support to local and regional actors. Committee of the Regions.

Barbosa, C. (2015). Políticas públicas locais para o envelhecimento: o caso de Portugal e da Suécia. EXEDRA: Revista Científica, 152-175. Disponível em http://www.exedrajournal.com/?p=426.

Bárrios, M. J. (2017). Políticas de envelhecimento ao nível local: análise e avaliação de programas a partir do paradigma de envelhecimento $\quad$ ativo. Lisboa. $\quad$ Disponível em https://www.repository.utl.pt/bitstream/10400.5/14078/1/Tese na Íntegra MJBárrios.pdf.

Braun \& Clarke. (2006). Using thematic analysis in psychology, Qualitative Research in Psychology, 3(2), 77101.

Costa, A., \& Santos, P. (2014). As imagens do envelhecimento e as práticas idadistas em cuidados de saúde primários: implicações na actividade física dos idosos. Revista de Psicologia, 1(2), 161-170.

Daniel, F., Antunes, A., \& Amaral, I. (2015). Representações sociais da velhice. Análise Psicológica, 33(3), 291301.

Decreto-Lei . $^{\circ}$ 115/2006. Diário da República n. ${ }^{\circ}$ 114/2006, Série I-A (2006). Acedido a 1 nov. 2018. Disponível em https://dre.pt/pesquisa/-/search/344943/details/maximized.

EUROSTAT. (2020). Population structure and ageing. Eurostat Statistics Explained. Acedido a 9 maio. 2020. Disponível em https://ec.europa.eu/eurostat/statisticsexplained/index.php?title=Population_structure_and_ageing/pt.

Fernández-Ballesteros, R. (2008). Active aging: The contribution of psychology. Cambridge: MA: Hogrefe \& Huber Publishers.

Fernández-Ballesteros, R., Robine, J. M., Walker, A., \& Kalache, A. (2013). Active aging: a global goal. Current Gerontology and Geriatrics Research, 1-4. doi:http://dx.doi.org/10.1155/2013/298012.

Ferrão, J. (2015). Ambiente e território: para uma nova geração de políticas públicas com futuro. In V. Soromenho-Marques \& P. T. Pereira (Eds.), Afirmar o futuro: políticas públicas para Portugal (pp. 328-336). Lisboa: Fundação Calouste Gulbenkian.

Fontaine, R. (2000). "Aspectos psicológicos". Envelhecimento. Lisboa: Climepsi Edditores.

Gonçalves, C. (2015). Envelhecimento bem-sucedido, envelhecimento produtivo e envelhecimento ativo: reflexões. Estudos Interdisciplinares sobre o envelhecimento, 20(2), 645-657.

Harper, S. (2010). The capacity of social security and health care institutions to adapt to an ageing world. International Social Security Review, 63(3-4), 177-196. doi:10.1111/j.1468-246X.2010.01374.x.

IESE. (2012). Projeto Rede em Prática -Relatório Final da Avaliação do Programa Rede Social. (R. Godinho \& J. M. Henriques, Eds.). Lisboa: Instituto de Estudos Sociais e Económicos. Disponível em http://www.cmamadora.pt/images/INTERVENCAO_SOCIAL/REDE_SOCIAL/PDF/rel_aval_prog_rsocial_iese2012.pdf.

Johnson, R. B., \& Onwuegbuzie, A. J. (2004). Mixed methods research: a research paradigm whose time has come. American Educational Research Association, 33(7), 14-26. 
José, J., \& Teixeira, A. (2014). Envelhecimento ativo: contributo para uma discussão crítica. Análise Social, 49(210), 28-54.

Kreling, N. H. (2010). O envelhecimento do trabalhador impõe novos desafios às políticas públicas. In XVII Encontro Nacional de estudos Populacionais. Caxambu: ABEP.

Marques, S. (2011). Discriminação da Terceira Idade. (FFMS, Ed.).

Matos, M. (2013). Governança e políticas públicas em territórios de baixa densidade. Instituto de Ciências Sociais da Universidade de Lisboa.

Naue, U., \& Kroll, T. (2010). Bridging policies and practice: challenges and opportunities for the governance of disability and ageing. International Journal of Integrated Care, 10(2). doi:http://doi.org/10.5334/ijic.522.

OMS. (2008). Guia global: cidade amiga do idoso. Suiça: World Health Organization.

Pereira, D. (2011). Políticas Públicas de Ação Social. Universidade Técnica de Lisboa.

Rossel, N., Herrera, R., \& Rico, M. (2004). Introducción a la Psicogerontologia. Madrid: Ediciones Pirâmide.

Ruivo, F. (1990). Local e Política em Portugal: o Poder Local na mediação entre o Centro e a Periferia. Revista Ciêntifica de Ciências Sociais, 30.

Sander, M., Oxlund, B., Jespersen, A., Krasnik, A., Mortensen, E. L., Westendorp, R. G., \& Rasmussen, L. J. (2015). The challenges of human population ageing. Age and Ageing, 44(2), 185-187.

Stoker, G. (2019). Can the governance paradigm survive the rise of populism? Policy \& Politics, 47(1).

Teles, F., \& Moreira, J. M. (2016). Liderança Ética num Contexto de Governação Local: Estado, Mercado e Sociedade Civil.

Tsukamoto, M. (2017). Governança multiníveis em territórios de baixa densidade: as comunidades intermunicipais do Alto Alentejo e da Beira Baixa. Universidade Nova de Lisboa.

Walker, A., \& Maltby, T. (2012). Active ageing: A strategic policy solution to demographic ageing in the European Union. International Journal of Social Welfare, 21, 117-130. doi:10.1111/j.1468-2397.2012.00871.x. 